\title{
Informal learning in work environments: training with the Social Web in the workplace
}

\author{
Francisco J. García-Peñalvo ${ }^{\mathrm{a} *}$, Ricardo Colomo-Palacios ${ }^{\mathrm{b}}$ and Miltiadis D. Lytras ${ }^{\mathrm{c}}$ \\ ${ }^{a}$ Computer Science Department/Science Education Research Institute/GRIAL Research Group, University of Salamanca, \\ Salamanca, Spain; ${ }^{b}$ Computer Science Department, Universidad Carlos III de Madrid, Leganés, Spain; ${ }^{c}$ Computer Information \\ Systems Department, The American College of Greece, Aghia Paraskevi, Greece
}

(Received 25 January 2012; final version received 19 March 2012)

\begin{abstract}
The Internet and its increasing usage has changed informal learning in depth. This change has affected young and older adults in both the workplace and in higher education. But, in spite of this, formal and non formal course based approaches have not taken full advantage of these new informal learning scenarios and technologies. The Web 2.0 is a new way for people to communicate across the Internet. Communication is a means of transformation and knowledge exchange. These are the facts that cannot be obviated by the organisations in their training programmes and knowledge management. This special issue is devoted to investigating how informal learning changes or influences online information in Social Web and training strategies in institutions. In order to do so, five papers will present different approaches of informal learning in the workplace regarding Web 2.0 capabilities.
\end{abstract}

Keywords: informal learning; Social Web; training; workplace; competence; skill; knowledge management

\section{Introduction}

Web 2.0 or Social Web (O'Reilly 2007) is changing the way users express themselves on the Internet. Everyone has the possibility to be a content author, a photographer, a video maker, a blogger and a thousand other possibilities.

The social activities that occur in the Web 2.0 open and expand communication and interaction scenarios. Therefore, there is an information interchange taking place beyond interactions, which is the perfect seed for informal learning.

Cross (2007) states that 'workers learn more in the coffee room than in the classroom'. Perhaps, using this metaphor, Web 2.0 or, more specifically, social networks are the new coffee rooms.

However, the question resides in whether companies and other kinds of institutions have discovered the power of the Social Web for informal learning and permanent learning, combining it with the traditional training methods.

Editors aim to study successful and unsuccessful cases of Social Web platforms used for informal learning in training processes linked to the workplace. Editors are also interested in technical concerns of the platforms used for this purpose. In this sense, questions pile up: Are these platforms ad hoc ones? Are these platforms started from scratch? Are these platforms mashup applications integrated in corporate portals? Do the existing learning environments support new social tools? Do institutions bet for opening new learning environments? How about the workers?

This special issue is devoted to dealing with the questions above. This includes a wide range of topics, but we are especially interested in the current practices to manage informal learning in workplaces based on Web 2.0 solutions. This issue intends to emphasise how informal learning changes or influences online information in Social Web and training strategies in various institutions.

\section{Knowing the informal learning context}

The concept of informal learning was introduced by Dewey (1938). This author considered that experience arises from the interaction of two principles: continuity and interaction. Continuity is that each experience a person has will influence his/her future, for better or for worse, while interaction refers to the situational influence on one's experience. Malcolm Knowles is another important reference in the origins of informal learning due to his attempts to develop a distinctive conceptual basis for adult education and learning via the notion of andragogy. This is based on the following concepts: self-concept, experience oriented, readiness to learn, orientation to learning and motivation to learn. He refers to informal learning as the use of informal programmes and, to some extent, the learning 
gained from associational or club life. According to this author, an organised course is usually a better instrument for new learning of an intensive nature, while a club experience provides the best opportunity for practising and refining the things learned (Knowles 1950).

More contemporary definitions on informal learning are, for example, the spontaneous and nonstructured learning that occurs in our daily life that go by in different contexts (Coombs 1985): any activity involving the pursuit of understanding, knowledge or skill which occurs outside the curricula of educational institutions, or the courses or workshops offered by educational or social agencies (Livingstone 1999). Finally, Cross (2009) stated that informal learners usually set their own learning objectives. They learn when they feel a need to know. The proof of their learning is their ability to do something they could not do before. Informal learning is often a pastiche of small chunks of observing how others do things, asking questions, trial and error, sharing stories with others and casual conversation. Learners are pulled to informal learning.

Nowadays, technological and organisational innovation and, in particular, the affordances of the Internet are facilitating an increasing access to knowledge and training for individuals. That ranges from formal courses to informal ad hoc learning. However, the greater part of the informal learning remains unacknowledged, both inside and outside institutional and organisational contexts. Though informal learning has always taken place, the advent of Information and Communication Technologies (ICT), particularly social media, has facilitated these processes and made them more perceptible. Nevertheless, there is an actual need for methodologies and tools to make visible these activities. Learners need to have a way to show the competences they have achieved by using informal environments along with a means to know what competences are the most relevant for a given institution. Moreover, they should take advantage of information generated by the system to find other users with similar interests. The information in the system will be useful both for users to demonstrate their learning and for employers and tutors to mentor their informal learning.

As a result of its importance, informal learning is increasingly seen as an aspect of learning that requires attention. For example, the CEDEFOP 'European Guidelines for Validating Informal and Non-formal Learning' (2009) contains experiences of more than 20 countries in the validation of informal and nonformal learning. The ECOTEC European Inventory of validation of non-formal and informal learning (http:// www.uk.ecorys.com/europeaninventory/) provides a catalogue of good practices in the area of validation for policy-makers. There are also several initiatives regarding informal learning practice and recognition, such as MyElvin Social Network for language practice (García-Peñalvo et al. 2012), National Qualification Systems and European Qualifications Framework, TENCompetence project (Berlanga et al. 2008) that provides a set of tools to support lifelong learning or FREE (Fostering Return to Employment through Entrepreneurship, Innovation and Creativity) that aimed at providing an interactive tool to be used by those who work with the unemployed, allowing them to gain different kinds of skills to support individuals who want to start a business (http:// www.spi.pt/free/).

\section{Contents of this special issue}

In this special issue, we are glad to introduce five innovative and interesting works that present different informal learning conceptions under the auspices of Web 2.0 philosophy.

Valencia-García et al., in their paper 'Informal Learning through Expertise Mining in the Social Web', introduce a semantic platform that allows an expertise mining from Social Web-generated content. This tool, given a topic of interest, carries out natural language processing and semantically enhanced operations on blog and microblog posts to identify experts in that specific topic area.

Milovanović et al.'s contribution is entitled 'Wiki as a Corporate Learning Tool: Case Study for Software Development Company'. In this paper, authors present the use of wikis as a knowledge exchange tool for companies with the focus on informal learning in a case study of a multinational software development company. Such company has been successfully using wiki as a corporate tool since 2001 with quite interesting results in the company knowledge management strategy.

The paper entitled 'Knowledge Exchange through Social Links in the Workplace', by Filipowski et al., underlines the huge importance of the knowledge exchange between employees within companies. Authors introduce SocLaKE, a knowledge management system based on social links gathered by various information technology systems. Users of such a system ask their queries and the system recommends known and unknown experts selected out of user's friends. The friends either provide the solution or forward the query to their friends. By means of the established social paths to experts, the system facilitates informal learning and exchange of latent knowledge between organisation members in their workplace. 
Christ et al., with their paper entitled 'Evaluation of Fostering Students' Creativity in Preparing Aided Recalls for Revision Courses Using Electronic Revision and Recapitulation Tools 2.0 (EREP 2.0)', introduce an evaluation of EREP 2.0. This tool was developed to foster creative moments while producing aided recalls (pictures, electronic notes, etc.). The result of this study shows an enhancement of the experience of creativity and thus an improvement of the synthesis and comprehension skills in an informal learning scope.

The last paper in this special issue is entitled 'Challenges of Knowledge Management and Creation in Communities of Practice Organisations of Deaf and Non-Deaf Members: Requirements for a Web Platform', by Trindade et al. In this work, authors present a very interesting case study of a community of practice that includes deaf members and in which the knowledge management tools play a very central role.

In conclusion, we would like to take this opportunity to thank authors who have contributed to this special issue. We would also like to acknowledge the help provided by the reviewers. We also want to thank Ahmet Cakir, Editor-in-Chief of Behaviour \& Information Technology for his endless support during the editorial process.

The set of papers in this issue shows the importance of the Social Web for informal learning in work environments. We hope that readers find the papers of this volume useful and innovative.

\section{Acknowledgements}

This project has been funded with the support of the Lifelong Learning Program of the European Union
TRAILER Project (Reference: 519141 LLP 120111 ES KA3 KA3MP) and with the support from the European Commission. Also, this work is partially supported by the Regional Council of Education of Junta de Castilla y León through the project GR47. This publication only reflects the views of the authors, and the commission cannot be held responsible for any use which may be made of the information contained therein.

\section{References}

Berlanga, A.J., et al., 2008. Towards a TENCompetence ePortfolio. International Journal of Emerging Technolo gies in Learning, 3, 2428.

CEDEFOP, 2009. European guidelines for validating non formal and informal learning. Luxembourg: Office for Official Publications of the European Communities.

Coombs, P.H., 1985. The world crisis in education: a view from the eighties. New York: Oxford University Press.

Cross, J., 2007. Informal learning. Rediscovering the natural pathways that inspire innovation and performance. San Francisco, CA: John Wiley.

Cross, J., 2009. Informal Learning 2.0. Sustaining the cor poration in the network era. Chief Learning Officer, 8 (8), 16.

Dewey, J., 1938. Experience and education. New York: Collier Books (Collier edition first published 1963).

García Peñalvo, F.J., González González, J.C., and Murray, M., 2012. MyElvin: a Web based informal learning plat form for languages practice. International Journal of Knowledge Society Research, 3 (1), 2639.

Knowles, M.S., 1950. Informal adult education. Chicago: Association Press.

Livingstone, D., 1999. Exploring the icebergs of adult learning: findings of the first Canadian survey of informal learning practices. Canadian Journal for the Study of Adult Education, 13 (2), 4972.

O'Reilly, T., 2007. What is Web 2.0: design patterns and business models for the next generation of software. International Journal of Digital Economics, 65, 1737. 